\title{
ALTERNATIVA PARA DESINFECÇÃO E RECICLAGEM DE SACOS PLÁSTICOS UTILIZADOS PARA O ACONDICIONAMENTO DE RESÍDUOS SÓLIDOS DE SERVIÇOS DE SAÚDE (RSSS)
}

\section{Francisco José Moreira Chaves ${ }^{1}$}

\author{
Messias Borges Silva ${ }^{2}$
}

Palavras-chave: Desinfecção, reciclagem, resíduo, saco plástico, ácido peracético.

\section{INTRODUÇÃO}

A crescente consciência sobre os ricos a saúde publica e ao ambiente, provocados por resíduos sólidos de serviços de saúde (RSSS), deve-se principalmente, as sua frações infectantes.

Surpreendentemente, no Brasil, há mais de 30 mil unidades de saúde produzindo esses resíduos, e na maioria das cidades, a questão do manuseio e da disposição final não está resolvida.

Os resíduos de serviço de saúde (RSS) são de natureza heterogênea, portanto é necessária uma classificação para a segregação desses resíduos.

Pela Resolução CONAMA N³58/2005 e pela Resolução ANVISA RDC N³06/2004 os RSSS são classificados em resíduos do grupo A, B, C, D e E. Essa Resolução ANVISA, que dispõe sobre o Regulamento Técnico para o gerenciamento de resíduos de serviços de saúde, estabelece de forma geral, que o sistema de tratamento dos resíduos Grupo A (resíduos com possível presença de agentes biológicos que por sua característica de maior virulência ou concentração, podem apresentar risco de infecção),

\footnotetext{
${ }^{1}$ Universidade de León, Fundação Universitária Iberoamericana - Funiber - francisco@iaap.org.br

${ }^{2}$ Professor Doutor - Universidade de León, Fundação Universitária Iberoamericana - Funiber
} 


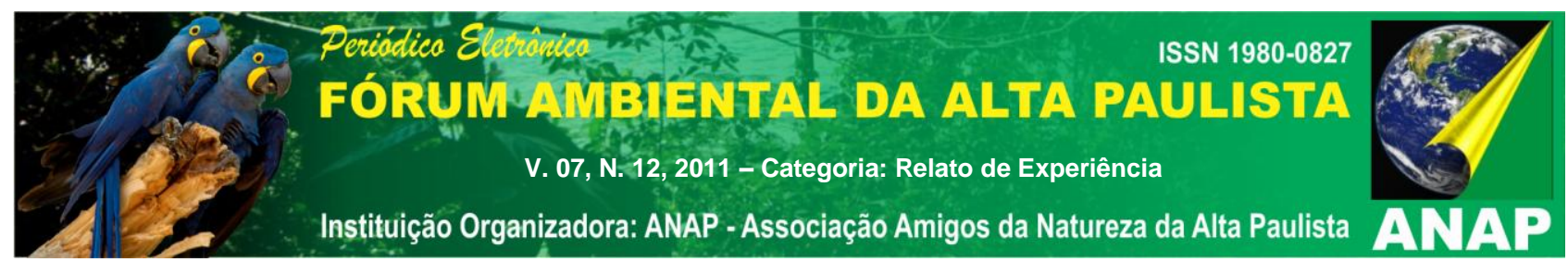

e os de Grupo E (materiais perfurocortantes ou escarificantes), ambos devem contemplar a redução de carga microbiana em equipamento compatível com a inativação microbiana, ou seja, inativação de bactérias vegetativas, fungos, vírus lipofílicos e hidrofílicos parasitas e micobactérias.

Independente da tecnologia a ser adota para o tratamento do resíduo, este tratamento terá que atender às seguintes condições: reduzir ou eliminar a carga microbiana; atender aos padrões estabelecidos pelo órgão de controle ambiental; ser um empreendimento ambientalmente correto e economicamente viável (RUSSO, 2003).

\section{OBJETIVO GERAL}

Desinfecção química de sacos plásticos utilizados para o acondicionamento de resíduos sólidos de serviços de saúde (RSSS), buscando assegurar as condições ou premissas técnicas para reciclagem.

\section{OBJETIVOS ESPECÍFICOS}

Demonstrar os sacos plásticos utilizados em serviços de atendimento a saúde para atividades hospitalares, como A4, Item 5 da alínea d, do Item I - Grupo A do Anexo I da Resolução CONAMA 358/2005; submeter amostras de sacos plásticos utilizados como recipientes de RSSS ao processo de desinfecção química por imersão em solução de ácido peracético; comprovar a eficácia do ácido peracético como desinfetante químico de alto nível através da ausência dos microrganismos Escherichia coli e Staphylococcus aureus presentes nos sacos plásticos; sugerir o encaminhamento do resíduo de plástico desinfetado para sistemas de reciclagem, proporcionando uma destinação ambientalmente correta.

\section{METODOLOGIA}

O trabalho experimental consistiu de ensaios de desinfecção em escala de laboratório, por processo seqüencial ou batelada, onde amostras de sacos plásticos foram submersas por períodos distintos, de 30 ou 45 minutos, em solução de ácido peracético com concentrações de $0,1 \%$ ou $0,25 \%$, e submetidos ou não a agitação mecânica intermitente. A partir destes experimentos obtem-se como resultados esperados, a serem obtidos pelo 


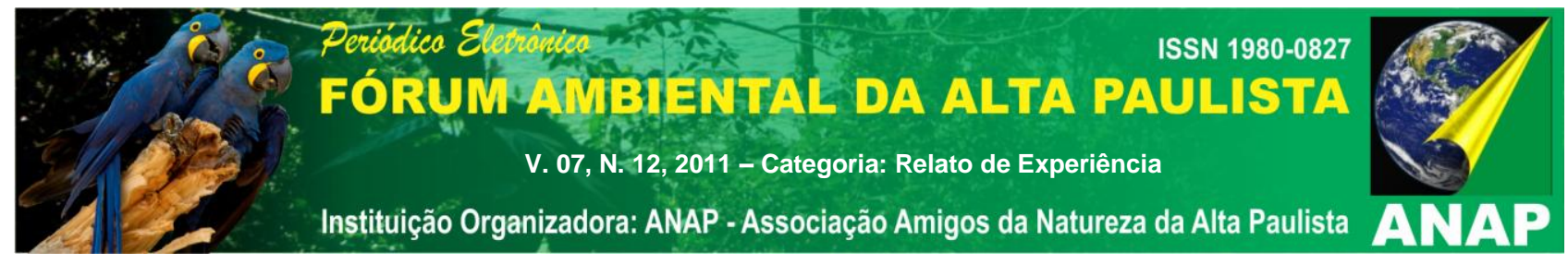

processo de desinfecção proposto, a ausência ou a redução significativa das unidades formadoras de colônias (UFCs) dos microrganismos Escherichia coli e Staphylococcus aureus, quando estes se encontravam presentes nas amostras.

$\mathrm{Na}$ análise dos dados foram utilizados métodos estatísticos que permitirão maior objetividade à tomada de decisão.

A escolha dos microrganismos foi definida a partir de revisão da literatura, sendo utilizadas informações especificas sobre a caracterização microbiológica de RSSS, e a avaliação de riscos de contaminação destes resíduos no ambiente.

As amostras de sacos plásticos (Plast Bag), tipo Hamper, (Polietileno de Alta Densidade) foram fornecidas pela empresa ATMOSFERA SA, empresa de gestão e higienização de têxtil de hospitais, indústrias, e hotelaria, localizada na cidade de Jundiaí, SP. Estes sacos plásticos são utilizados por hospitais para acondicionar e transportar rouparias sujas oriundas de centros cirúrgicos incluindo: roupas de pacientes, lençóis, fronhas, toalhas, jalecos.

Os sacos plásticos (Plast Bag), por sua descrição e características físicas podem ser classificados como Resíduos de Classe A4 Item 5, com base no Anexo I da Resolução CONAMA Nº 358 de 29/04/2005.

Todos os procedimentos descritos foram realizados no Laboratório de Microbiologia da empresa GESCO - Projetos, Comércio e Representações Ltda, o qual é credenciado pelo Instituto Estadual do Ambiente (INEA) do Estado do Rio de Janeiro. Os profissionais que atuaram na realização dos experimentos são qualificados e treinados, e devidamente registrados nos seus respectivos órgãos de classe (Conselho Regional de Biologia e Conselho Regional de Química).

\section{RESULTADOS}

Para estes ensaios preliminares foram fornecidas pela empresa ATMOSFERA SA um total de 30 amostras de sacos plásticos, sendo que dentre estas 24 amostras foram submetidas aos experimentos de desinfecção química por imersão.

Após o processo de extração da carga microbiana, antes da desinfecção das 24 amostras de sacos plásticos utilizadas, todas apresentaram resultados positivos para UFCs da espécie bacteriana Staphylococcus aureus. Com relação à bactéria Escherichia 


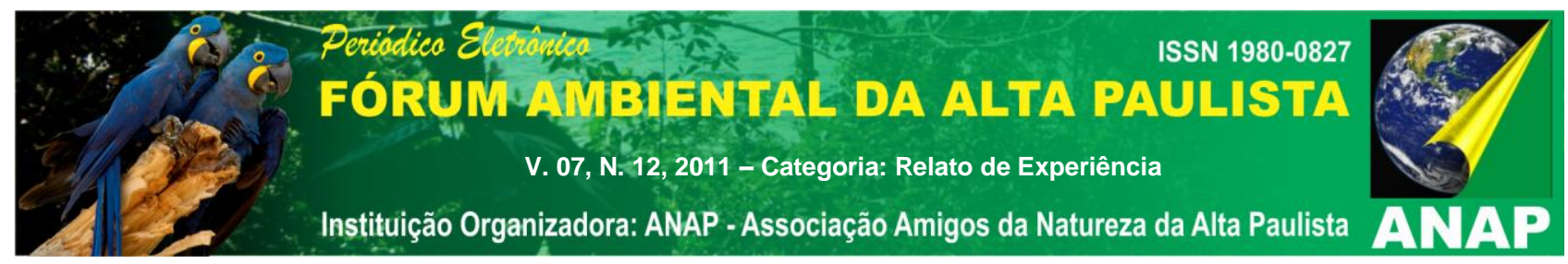

coli, todas as 24 amostras apresentaram resultado negativo quanto ao crescimento de UFCs.

O resultado para o teste de controle confirmou a presença de $S$. aureus com UFCs similares, e ausência de E. coli, antes e depois deste teste, fato que ratifica que apenas a água clorada não tem função como agente desinfetante neste processo. O resultado para o teste negativo de bancada confirmou a ausência de ambas as espécies bacterianas, $S$. aureus e E. coli.

Foram realizados oito experimentos, sendo cada um efetuado em triplicata em relação aos níveis ou variáveis de controle: concentração de ácido peracético, tempo de reação, agitação intermitente.

De um total de 24 amostras experimentadas, nove amostras apresentaram desempenho de $100 \%$, isto é, apresentaram inativação bacteriana total. Não houve evidência de colônias da bactéria Escherichia coli nas 24 as amostras de sacos plásticos, antes e depois, do processo de desinfecção por imersão.

Com o uso do software STATISTICA 9.0, os dados obtidos nos experimentos delineados na Matriz de Experimentos projetada foram trabalhados estatisticamente com vistas a favorecer o entendimento de cada variável e da interação entre elas, na efetiva influência quanto às "variáveis resposta" dentro das condições tecnológicas estabelecidas.

\section{CONSIDERAÇÕES FINAIS}

Os estudos realizados demonstraram que os sacos plásticos, com leve suspeita de contaminação poderiam ser classificados como A4, Item 5 da alínea "d" do Item I - Grupo A do Anexo I da resolução em pauta, e portanto não poderiam ser reciclados (Art. 20 da Resolução CONAMA 358/2005), podem ter tratamento alternativo visando sua reciclagem.

O desenvolvimento de uma tecnologia de tratamento capaz de reduzir ou inativar microrganismos faz com que os resíduos pesquisados não constituam uma ameaça, mas sim, uma real oportunidade, que contempla os aspectos econômico, social e ambiental. 


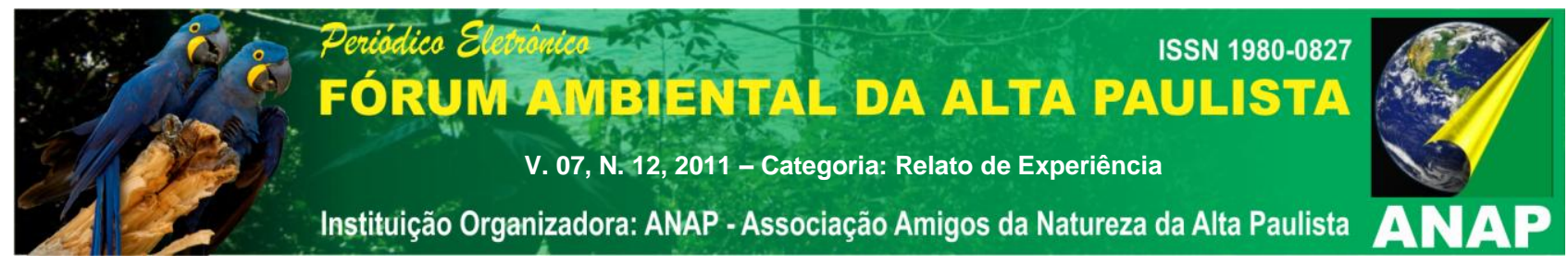

O presente trabalho revela e esclarece a oportunidade de se adotar a desinfecção química como tecnologia de gestão de RSSS antes da hipótese de simples destinação final.

Mediante os resultados obtidos recomendam-se para trabalhos futuros:

- Estudar e realizar testes com mudanças de valores dos níveis de controles;

- Estudar a hipótese de se incluir a variável temperatura;

- Rever e delinear nova matriz de experimentos com base nas recomendações anteriores;

- Estudar e definir a necessidade para se realizar análises microbiológicas de outras espécies;

- Aprimorar e consolidar os procedimentos operacionais para a escala industrial;

- Realizar a análise econômica do empreendimento com definição prévia de capacidade instalada.

\section{REFERÊNCIAS}

AGÊNCIA NACIONAL DE VIGILÂNCIA SANITÁRIA-ANVISA. Resolução RDC no 306, de 07-12-2004. Dispõe sobre o Regulamento Técnico para o gerenciamento de resíduos de serviços de saúde. Brasília, 2004.

CONSELHO NACIONAL DO MEIO AMBIENTE. Ministério do Meio Ambiente. Resolução no 358/2005, de 29-04-2005. Dispõe sobre o tratamento e disposição final dos resíduos de serviços de saúde. Brasília, 2004, 4 p.

RUSSO, M. A. Tratamento de Resíduos Sólidos. Coimbra: Universidade de Coimbra, Faculdade de Ciências e Tecnologia, Departamento de Engenharia Civil. 2003. p.196. 